do not support the conclusion that the activity of these salts is a normal atomic property of potassium, and that it is always directly proportional to the amount of that metal present in the salt.

In measuring and comparing the activities of the different salts, these were spread in turn in thin regular layers on a shallow tray, which was placed on the bottom of an ionising chamber $40 \mathrm{~cm}$. long, $26 \mathrm{~cm}$. wide, and $28 \mathrm{~cm}$. deep. The saturation currents through the air in this chamber were measured with a sensitive quadrant electrometer, and were taken as measures of the activities of the different salts. Experiment showed that the saturation current increased with the thickness of the salt layer up to between $2 \mathrm{~mm}$. and $3 \mathrm{~mm}$., and for greater thicknesses remained constant.

The investigation included the examination of some thirty specimens of potassium salts, and thirteen samples of the salts of the other alkali metals. As a result of this examination it was found:-

(1) That samples of a selected potassium salt obtained from different sources exhibited widely differing degrees of activity. Two chlorides of potassium, for example, were found to differ by more than 40 per cent. in their activities, and two of hydroxides by an almost equal amount. In the case of cyanide of potassium, the variation in activity was especially marked, as two samples of this salt exhibited activities which were approximately only 5 per cent. and 20 per cent. respectively of that shown by a number of other samples of the same composition. A sample of potassium sulphite, too, was found to possess an extremely small activity.

With the majority of the salts, however, the variations were not so marked, but the differences observed; even when due allowance was made for the varying densities and states of division of the salts, were so extensive and of such magnitude as practically to preclude the view that the activity of potassium and its salts was connected with a normal atomic property of the metal.

(2) That while metallic sodium and several sodium salts did not exhibit the slightest trace of activity, some samples of sodium chloride, obtained in the form of rock salt, showed an activity comparable with that exhibited by a number of the potassium salts. This result, taken in conjunction with the low value obtained by Elster and Geitel in their measurements on the conductivity of air in a salt mine, would indicate that very probably some active impurity was present in the samples of rock salt examined.

(3) That with the exception of ammonium chloride, which exhibited a feeble activity, none of the lithium and ammonium salts examined showed the slightest trace of radio-activity; that a sample of rubidium alum was found on examination to exhibit an extremely small activity, and that a sample of casium chloride exhibited one which was only just measurable.

University of Toronto, April I5.

\section{Chemical Analyses of Water from Dew Ponds.}

I HAVE been interested in the reviews of books and articles which have appeared in NATURE from time to time on the subject of dew ponds; and it occurred to me that the chemical analysis of the water of these ponds would help to settle the question of the origin of the water. This is a method used to some extent by sanitary authorities. I have had the opportunity of obtaining some specimens of water from different districts, and the specimens have been analysed by Mr. Claude Saville Grace, one of the students at this institute.

The first specimen (a) came from a dew pond on the southward down to the north of Ramsbury, Wiltshire. The pond is on the flat upland near the 693-feet mark on the r-inch Ordnance map south of Aldbourne. The formation is chalk, so that analysis would immediately settle the point as to whether the water had come through the chalk or had been condensed from the air. The other two specimens, (b), (c), come from St. Boniface Down, north of Ventnor, Isle of Wight. The pond (b) is near the 787 -feet mark, almost at the highest point of the down; the second pond $(c)$ is on the neck between St. Boniface and Shanklin Downs. The downs are chalk masses lying on Greensand rock. I have added the analysis of the St. Boniface spring water, a spring on the south side of the down facing Ventnor, about 450 feet above sea-level. It is locally known as a wishing well, and its chemical peculiarity is that it contains sulphuretted hydrogen in small quantity. It thdoubtedly comes out of the chalk, and the sulphuretted hydrogen is due to the decomposition of pyrites which occurs in masses in the chalk.

\begin{tabular}{|c|c|c|c|c|c|}
\hline & & $\begin{array}{l}\mathrm{CaCO}_{3} \\
\text { parts pex } \\
\text { I00,000 }\end{array}$ & & $\begin{array}{c}\mathrm{Cl} \text { parts } \\
\text { per } \\
\text { roo, } 000\end{array}$ & \\
\hline $\begin{array}{l}\text { (a) Ramsbury pond } \\
\text { (b) St. Boniface pond }\end{array}$ & & $\ldots 36$ & $\ldots$ & 0.75 & inland \\
\hline (b) St. Boniface pond & $\ldots$ & $\ldots 43$ & $\ldots$ & $3 \div 5$ & near sea \\
\hline $\begin{array}{l}\text { (c) Shanklin pond ... } \\
\text { (d) St. Boniface Wishi }\end{array}$ & & all $\quad 7 \% 7$ & $\cdots$ & $3 \cdot 4$ & 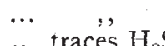 \\
\hline
\end{tabular}

The quantities of $\mathrm{CaCO}_{3}$ indicate to me that the waters are, in the cases $(a),(b),(c)$, condensed waters which have been lying in the pond sufficiently long to take up a little $\mathrm{CaCO}_{3}$. The ponds near the sea show increased chlorine, probably from salt spray blown up from the sea. The sulphuretted hydrogen' shows the origin of the wishingwell water in the deep chalk.

To me there is very little doubt that all three ponds are simply water butts in which rain water is stored. Inspection of the ponds shows that they have much larger catchment areas than simply the water area, and the area is generally more than nine times that of the pond. We have to remember that for circular ponds and catchment areas of radii $I$ and 3 respectively a rainfall of 20 inches would mean a depth of 180 inches ( ${ }_{5}$ feet) when collected into the pond area, so we can easily understand the presence of water all the year round under these conditions.

It is interesting to note that a fresh-water pond is easily distinguished from the hard-water pond by the waterweed growing in the former. I have noticed. the same carex in all the fresh-water ponds. SIDNEY SkINNER.

South-Western Polytechnic Institute, May 8.

\section{The Reflection of Distant Lights on the Clouds.}

I Do not know whether observations have ever been made to determine how far the reflection of distant lights on the clouds may be seen. It may possibly, however, be of some interest to know that the lights of London may at times be seen in this way at a distance of at least fifty miles. At I I p.m. on April 30 the reflections of the lights of several neighbouring towns were unusually bright as seen-from here. The altitude of the Portsmouth glare was about $10^{\circ}$; the distance of the centre of Portsmouth is about 12.5 miles; the cloud height was therefore about 2.2 miles. Over Hindhead and Blackdown a bright band of light was visible. Circumstances prevented me from measuring its altitude, but I estimated it as one or two degrees. Now London lies exactly in this direction, and fifty miles would bring one to the well-lighted area of south London. If the cloud height were uniform, the altitude of the reflection at this distance should have been a little more than $2^{\circ}$. The only other large town in the same direction is Guildford; the altitude of its glare should have been $5^{\circ}$. I do not think I could have made so large an error in estimating the altitude, but apart from this the Guildford glare would not stretch along. the horizon for more than $2^{\circ}$, while the observed band of light stretched for at least $10^{\circ}$, and possibly more, for trees bounded the view to the west and the downs to the east.

Ditchani Park, Petersfield, May 9.

$$
\text { Charles J. P. Cave. }
$$

\section{Jupiter's Eighth Satellite.}

ThE discovery at Greenwich Observatory of Jupiter's eighth satellite, its great distance from the planet, and its retrograde motion, have excited the interest of the astronomical world.

Until more extended observations have led to a more certain knowledge of the orbit, speculation is premature. But it is impossible to resist the conjecture that there is a bare possibility that the object is really the long lost Lexell's comet, which in $177^{\circ}$ was describing an elliptic orbit with an eccentricity of $0.785^{8}$, with a periodic time

$$
\text { NO. } 201 \mathrm{I} \text {, VOL. } 78 \text { ] }
$$

